\title{
Effect of Hydrothermal Treatment on the Nutritional and Functional Properties of Husked and Dehusked Buckwheat
}

Shruti Pandey ${ }^{1 *}$, Amudha Senthil ${ }^{2}$ and Kahkasha Fatema ${ }^{1}$

${ }^{1}$ Department of Grain Science and Technology, CSIR-Central Food Technological Research Institute, Mysore, 570020, India

${ }^{2}$ Sensory Science, CSIR-Central Food Technological Research Institute, Mysore, 570020, India

\begin{abstract}
Buckwheat (Fagopyrum esculentum) is a rich source of many bioactive components, which have been shown to provide various health benefits. In the present investigation, effect of hydrothermal treatment on the buckwheat seeds and changes in physico-chemical and functional properties (of husked and dehusked flours) were studied. Results revealed that, the protein content decreased as the duration of parboiling increased whereas crude lipid, fiber and ash content increased in both the husked and dehusked flours. It was also observed that the mineral content was higher for the husked as compared to dehusked flours. Hydrothermal processing increased swelling power and solubility. The product developed from the dehusked flour was preferred over the husked flour product.
\end{abstract}

Keywords: Biscuits; Buckwheat flour; Cereal and grains; Dietary fiber; Textural profile analysis

\section{Introduction}

Cereal and cereal products are one of the most important staple foods. About two billion tonnes of cereals are produced in the world annually. The major cereals of the world are: wheat, rye, barley, oats, maize, rice, millet and sorghum. All cereals are members of the grass family. Pseudocereals are available as an alternative to these cereals. Although many plants from the family chenopodiaceae are used for human nutrition (e.g. spinach, beet), only three plants Buckwheat, Quinoa and Amaranthus have gained importance as grains, so called pseudo-cereals, worldwide. Botanically they are assigned to the dicotyledonous, but they all produce starch-rich seeds that can be used like cereals. All three pseudocereals have advantageous nutritional properties and are very well able to increase the range of starch rich plants for human nutrition [1]. Buckwheat (Fagopyrum esculentum) belonging to the family Polygonaceae is a moisture loving, coolclimate, annual cereal crop [2]. It is a native of Central Asia, cultivated in China and other Eastern countries as a bread-corn. There are two well-known varieties of buckwheat mainly Fagopyrum esculentum Moench and Fagopyrum tataricum (L.) Gaertn. Fagopyrum esculentum Moench is widely grown in India as compared to the other variety. It is silvery grey to brown or black in colour [3]. It takes about 90-100 days to harvest the crop and can grow well in fertile land [4]. The seed coat is green or tan, which darkens the buckwheat flour. The buckwheat fruit, is triangular in shape and measures about 4-9 $\mathrm{mm}$ long [5]. The outer layer of the achene is a dark brown or black fibrous hull (pericarp). Dehulled achenes are called groats. Buckwheat groats bear structural resemblance to traditional cereal grains. The kernel is made up of a testa, an aleurone layer, an embryo, and a central endosperm [6]. Its renewed popularity stems from its many bioactive components, which have been shown to provide various health benefits much sought after in natural foods. Due to their different morphology and different functional properties, the known cereal processing methods cannot be applied on processing of pseudocereals without adaptation, but their seed can be ground into flour and otherwise used as cereals. Buckwheat starch, proteins and flavanoids have been studied in detail, however effect of hydrothermal treatment on the grain properties have not been studied in detail. Parboiling technique (generally used to process rice) is claimed to improve the retention of proteins, vitamins and minerals during subsequent cooking. The effects of parboiling on the retention of nutrients within the grains are two folds [7]. Hence, an attempt is being made to study the effect of hydrothermal treatment on Buckwheat (husked, and dehusked) and study its effect on physicochemical, nutritional and functional characteristics of the grains.

\section{Materials and Methods}

Commercial samples of buckwheat seeds were procured from local market. After cleaning off the chaff, they were stored in cold room at $4^{\circ} \mathrm{C}$ and taken out as and when needed. Chemicals used for analysis purpose were of analytical grade.

\section{Materials}

Preparation of the flour sample: Cleaned buckwheat seeds were washed in excess water to remove adhering dust. Washed seeds were soaked in excess hot water $\left(80^{\circ} \mathrm{C}\right)$, about $4 \mathrm{hrs}$ at room temperature. After the soaking period the un-imbibed water was drained off. The buckwheat seeds were autoclaved at atmospheric pressure for 5 minutes, 10 minutes, and 15 minutes at $95^{\circ} \mathrm{C}$ respectively in an autoclave. Steamed samples were then air dried at $55^{\circ} \mathrm{C}$ for $6 \mathrm{hrs}$ until moisture content reached to about $7-9 \%$ in an hot air drier. The parboiled husked and dehusked samples along with control were milled in a laboratory scale grain mill (hammer mill). For the control samples, raw unhusked and husked buckwheat flour were grinded in a hammer mill. The milled samples were sieved through 60 mesh. The lower fraction $(-60)$ was used for the further analysis, they were stored in cold room at $4^{\circ} \mathrm{C}$ and taken out as and when needed. There were a total of 8 samples, HC-Husked Control buckwheat flour; HTAHusked 5 min parboiled flour (Treatment A); HTB - Husked 10 min parboiled flour (Treatment B); HTC-Husked 15 min parboiled flour (Treatment C); DHC-Dehusked Control buckwheat flour; DHTA-

*Corresonding author: Shruti Pandey, Department of Grain Science and Technology, CSIR-Central Food Technological Research Institute, Mysore, 570020, India, Tel: +91 821 2510843; Fax: +91 821 2517233; E-mail:shruti@cftri.res.in

Received April 08, 2015; Accepted May 14, 2015; Published May 21, 2015

Citation: Pandey S, Senthil A, Fatema K (2015) Effect of Hydrothermal Treatment on the Nutritional and Functional Properties of Husked and Dehusked Buckwheat J Food Process Technol 6: 461. doi:10.4172/2157-7110.1000461

Copyright: $\odot 2015$ Pandey S, et al. This is an open-access article distributed under the terms of the Creative Commons Attribution License, which permits unrestricted use, distribution, and reproduction in any medium, provided the original author and source are credited. 
Dehusked 5 min parboiled flour (Treatment A); DHTB-Dehusked 10 min parboiled flour (Treatment B); DHTC-Dehusked 15 min parboiled flour (Treatment C). Germinated flour was prepared by germinating the seeds for $72 \mathrm{hrs}$, which were then kilned at $60^{\circ} \mathrm{C}$ after devegetation (roasted), grinded in hammer mill and stored at $4^{\circ} \mathrm{C}$.

\section{Methods}

Physical, proximate and functional analysis: The samples of husked and dehusked parboiled buckwheat flour were analyzed for, physical proximate and functional properties. Physical properties of grains are of paramount importance in all the activities of production, preservation and utilization. Knowledge of physical properties is necessary right from harvesting, drying, handling and storage to milling, packing, cooking, product development and utilization. The dimensional parameters viz, thickness $(\mathrm{T})$ was measured with vernier calipers. The Gravimetric properties viz, weight of 1000 kernels of each sample was determined. The bulk density was determined using the mass/volume relationship. The true density defined as the ratio between the mass of seeds and the true volume of the grain, was determined using the kerosene displacement method. The frictional property viz, angle of repose of the buckwheat seeds were determined according to the method of Bhattacharya et al. [8]. Proximate analysis was done using standard methods of analysis. The moisture content of the buckwheat flour was determined after drying at $130^{\circ} \mathrm{C}$ for two hours. Crude lipids were extracted with petroleum ether, using a Soxhlet apparatus and ash contents (gravimetric) were determined based on methods outlined in AOAC (2000). The micro-Kjeldahl method was employed to determine the total nitrogen and the crude protein (NX5.95) [9]. Dietary fibre was estimated using the method of Englyst and Hudson [10]. Ash was estimated as per the method outlined in AOAC [9]. The free and bound polyphenols were extracted using $\mathrm{HCl}-$ methanol and assayed by Folin-Ciocalteu method with gallic acid as a standard [11]. Levels of potassium, calcium, zinc, magnesium and iron in buckwheat flour samples were determined by atomic absorption spectrophotometry (Perkin-Elmer, Analysis tA 700) after digestion with concentrated nitric acid.

Functional properties: Swelling power and solubility of husked and dehusked buckwheat flour were determined at temperature $30^{\circ} \mathrm{C}$, $45^{\circ} \mathrm{C}, 60^{\circ} \mathrm{C}, 75^{\circ} \mathrm{C}$ and $90^{\circ} \mathrm{C}$, according to the modified method of Unnikrishnan et al. [12]. Total Amylose from defatted buckwheat flour was estimated as per the method of Sowbhagya and Bhattacharya [13]. Potato amylose was used as a standard.

Scanning electron microscope: Scanned images of the buckwheat flour were obtained with a scanning electron Microscope (LEO 435VP, LEO Electron Microscopy Ltd., Cambridge, Electron). The flour was mounted on round aluminum stubs with the aid of double-sided adhesive tape. The samples were coated with gold $(\sim 100 \mu \mathrm{m})$ by means of a KSE $24 \mathrm{M}$ high vacuum evaporator and scanned. The selected regions were photographed at 5000X.

\section{Flour characteristics}

Color and Particle size measurement of flour-color values of the samples were determined by Hunter system $L$, a, b values. The colour of the product was measured in accordance with CIE L*, a*, b colour space system (Lab Scan XE Hunter Lab instruments, Virginia, USA) based on the tri stimulus value. In the Hunter system, positive 'a' value indicates redness and negative value indicates the greenness, the neutral is 0 . Positive ' $b$ ' value indicates yellowness and negative ' $b$ ' indicates blue and 0 is neutral. ' $L$ ' value represents lightness or brightness, where 0 is black and 100 is white. The samples were placed in the glass petri plate provided in the instrument, and readings were taken in triplicates. Samples sieved with 60 mesh were used for particle size analysis by using Microtrac Bluewave Particle size analyzer. The samples were placed in the glass petri plate provided in the instrument, and readings were taken in triplicates.

\section{Product development and sensory profile of biscuits}

Powdered control samples of husked, dehusked and germinated buckwheat flour were taken and sieved through 100 mesh. Fat was heated and soya lecithin was mixed to form emulsion. Sugar, milk powder and vanilla essence was mixed with fat to form a thick paste. Ammonium Bi-carbonate, sodium bi-carbonate and salt was mixed with flour and the paste was added to it. Paste and flour were mixed thoroughly and egg paste was added and dough was prepared. Dough was rolled and cut into finer shapes and kept for baking at $120-150^{\circ} \mathrm{C}$ for 20-25 min. Quantitative Descriptive Analysis (QDA) method was employed for profiling the samples. A suitable score card comprising selected sensory attributes (descriptors) was formulated for this purpose. Panelists were asked to mark on a scale of $0-15 \mathrm{~cm}$ to indicate the perceived intensity of each attribute listed on the score card. The scale was anchored at $1.25 \mathrm{~cm}$ on either end, representing 'Recognition Threshold' and 'Saturation Threshold' respectively. Scores given for all the attributes for each sample were tabulated. Next, mean value was calculated for each attribute of a sample representing the panel's judgment about the sensory quality of the product. The color of the biscuit was measured in accordance with CIE $\mathrm{L}^{*}, \mathrm{a}^{*}, \mathrm{~b}^{*}$ color space system (Lab Scan XE Hunter Lab instruments, Virginia, USA) based on the tristimulus value by placing the biscuit in the petri plate provided in the instrument. Texture measurement of biscuits prepared from flour was done with Lloyd (LR5K) texture meter, by applying load of $1 \mathrm{KN}$ and speed $50 \mathrm{~mm} / \mathrm{min}$.

\section{Statistical analysis}

The entire experiments were performed in triplicates, and the data presented as mean \pm standard deviation (SD). All statistical analysis was done using Microsoft Excel 2007 (Microsoft Corp., Redmond, WA, USA). Data were assessed for significant difference employing one way ANOVA and were considered to be statistically significant at $\mathrm{p}<0.05$.

\section{Results and Discussion}

\section{Physical and proximate composition of buckwheat}

The main parts of buckwheat kernels are: Hulls (husk), testa, aleurone layer, central (starchy) part of endosperm and embryo (including cotyledons). The agronomical characteristics of buckwheat are presented in supplementary Table 1. Grain size and shape are considered as important criteria for understanding the physical properties of grains. Coming on to the physical parameters in Table 1 , the grain diameter varied in the control and parboiled. In the parboiled (husked) the diameter $(1.94 \mathrm{~mm})$ and 1000 kernel weight $(25.08 \mathrm{~g})$ was high as compared to control $(1.81 \mathrm{~mm}$ and $24.09 \mathrm{~g})$, whereas in the parboiled dehusked $(1.58 \mathrm{~mm}$ and $23.89 \mathrm{~g})$ the diameter and weight was less. However no significant difference was observed for 1000 kernel weight in control and dehusked parboiled. The true density and bulk density was highest for dehusked parboiled buckwheat as compared to control and parboiled husked. Different parts of buckwheat kernel have very different chemical compositions. The hull is rich in fiber substances, whereas the testa is rich in tannins. The aleurone layer has abundance of proteins, whereas the endosperm is a store house for starch and few proteins. The embryo (including cotyledons) is very rich (about 50\%) in protein sand crude fiber [14]. Research has 
Citation: Pandey S, Senthil A, Fatema K (2015) Effect of Hydrothermal Treatment on the Nutritional and Functional Properties of Husked and Dehusked Buckwheat. J Food Process Technol 6: 461. doi:10.4172/2157-7110.1000461

shown that the bran, which consists of the aleuronic and embryonic tissues, is by far the richest milling fraction in macronutrient and dietary fibre content [15]. Because of the non-uniform distribution of nutrients throughout the grains, the nutrient losses during processing are nonlinear, and is characteristic for each nutrient. The proximate compositions of the two types of flours are presented in Table 2. The moisture content varied from $7-9 \%$ respectively in all the flours. No significant change was observed between the flours of HC and HTA and within DHC, HTB and HTC. The crude lipid content varied in the husked and dehusked flours. The crude lipid content increased as the duration of parboiling increased. There was an increase of $33 \%$ lipid in the husked whereas an increase of $68 \%$ was observed for the dehusked. Soral et al. $[16,17]$ reported that, the content of free lipids in buckwheat grain was twice higher than of bond lipids. The author also reported that after hydrothermal treatment there was an increase in free lipid content in the grain. The crude protein content decreased as the duration of parboiling increased, in the husked (30\%) as well as the dehusked (24\%). In all the treatments there was a significant difference in the crude protein content, however difference was not observed in HTB and DHC, and in HTC and DHTB. Bonafaccia et al. [18] reported levels of protein in grain, bran and flour of common buckwheat to be $11.7 \%, 21.6 \%$ and $10.6 \%$, respectively. It is also reported that Buckwheat is of high nutritive and medicinal value as the seed contains high crude protein content (18\%), with biological values above 90\% [19], containing a high concentration of all essential amino acids, especially lysine, threonine, tryptophan and the sulphur-containing amino acids. The ash content increased as the duration of parboiling increased. However the ash content was high in the husked as compared to dehusked. The increase in ash content in husked was $40 \%$ whereas for dehusked was
55\%. Significant difference was not observed in the ash content for HC, HTA, and DHTA. Also no significant difference was observed for HTB, HTC, DHTB and DHTC. Dietary fiber in buckwheat, is mostly concentrated in the seed coat and hull, which comprise the outer tissues of the buckwheat grain, dehulled seeds could contain as low as $7 \%$ fibre and concentrations in fancy flour could be five to ten times lower than in bran. In all, buckwheat seeds contain about $70 \%$ more DF than wheat grains [20]. From Table 3, it can be concluded that the fiber content in husked was high, as compared to dehusked. However the fiber content increased as the duration of parboiling increased, a 55\% increase was observed for the husked whereas a $76.2 \%$ for dehusked flours. No significant difference was found between the fiber content in HC, DHTB and DHTC (Supplementary Tables 1 and 2).

\section{Minerals}

Buckwheat is very rich in trace elements (for example $\mathrm{Zn}, \mathrm{Cu}$, $\mathrm{Mn}$ and Se), however, it must be grown in unpolluted areas, to avoid accumulation of contaminating elements. Different milling fractions may contain different minerals and proteins, dark flours being generally richer than the light ones [21].

Buckwheat also contains minerals such as potassium, iron, magnesium, manganese, zinc, copper [22] and B vitamins. The mineral composition of the husked and dehusked flours is presented in Table 2. There was no significant difference between iron content in the treatments between HC, HTA, and DHC. Also it was observed that there was no significant difference between DHTB and DHTC. Iron has the longest and best described history among all the micronutrients. It is a key element in the metabolism of almost all living organisms. In

\begin{tabular}{|l|l|l|l|}
\hline Physical parameters & Whole Buckwheat (Control) & Parboiled buckwheat (Husked) & Parboiled buckwheat (Dehusked) \\
\hline Thickness $(\mathrm{mm})$ & $1.79 \pm 0.08$ & $1.94 \pm 0.01$ & $1.58 \pm 0.02$ \\
\hline 1000 Kernel weight (grams) & $23.92 \pm 0.20$ & $25.14 \pm 0.17$ & $23.20 \pm 0.59$ \\
\hline True density $\left(\mathrm{kg} / \mathrm{m}^{3}\right)$ & $1291 \pm 2.08$ & $1310 \pm 1.15$ & $1391 \pm 1.52$ \\
\hline Bulk Density $\left(\mathrm{kg} / \mathrm{m}^{3}\right)$ & $768.53 \pm 2.52$ & $741.20 \pm 1.53$ & $813.71 \pm 1.55$ \\
\hline Angle of Repose $\left(^{\circ}\right)$ & $14 \pm 0.57$ & $11 \pm 1.00$ & $12 \pm 1.00$ \\
\hline
\end{tabular}

Means and Standard deviation of triplicate values are given. Values within the rows with same super script are not significantly different ( $\mathrm{P} \leq 0.05)$.

Table 1: Physical parameters of buckwheat.

\begin{tabular}{|c|c|c|c|c|c|c|c|c|}
\hline $\begin{array}{l}\text { Proximate } \\
\text { composition }\end{array}$ & $\begin{array}{l}\text { Control } \\
\text { Husked } \\
\text { (HC) }\end{array}$ & $\begin{array}{l}\text { Control } \\
\text { Dehusked } \\
\text { (DHC) }\end{array}$ & $\begin{array}{c}\text { TreatmentA } \\
\text { Husked } \\
\text { (HTA) }\end{array}$ & $\begin{array}{c}\text { Treatment A } \\
\text { Dehusked } \\
\text { (DHTA) }\end{array}$ & $\begin{array}{c}\text { Treatment B } \\
\text { Husked } \\
\text { (HTB) }\end{array}$ & $\begin{array}{c}\text { Treatment B } \\
\text { Dehusked } \\
\text { (DHTB) }\end{array}$ & $\begin{array}{c}\text { Treatment C } \\
\text { Husked } \\
\text { (HTC) }\end{array}$ & $\begin{array}{c}\text { Treatment C } \\
\text { Dehusked } \\
\text { (DHTC) }\end{array}$ \\
\hline Moisture & $6.94 \pm 0.09$ & $8.15 \pm 0.05$ & $7.27 \pm 0.31$ & $8.52 \pm 0.05$ & $7.71 \pm 0.15$ & $8.64 \pm 0.17$ & $7.82 \pm 0.05$ & $8.70 \pm 0.10$ \\
\hline Crude lipid & $3.94 \pm 0.04$ & $3.27 \pm 0.03$ & $4.28 \pm 0.08$ & $4.01 \pm 0.03$ & $4.60 \pm 0.05$ & $5.17 \pm 0.14$ & $5.26 \pm 0.20$ & $5.5 \pm 0.14$ \\
\hline CrudeProtein & $14.50 \pm 0.35$ & $12.00 \pm 0.11$ & $12.73 \pm 0.20$ & $10.93 \pm 0.13$ & $11.6 \pm 0.26$ & $10.06 \pm 0.12$ & $10.21 \pm 0.12$ & $9.16 \pm 0.07$ \\
\hline Ash & $2.18 \pm 0.02$ & $1.7 \pm 0.20$ & $2.42 \pm 0.11$ & $1.89 \pm 0.04$ & $2.81 \pm 0.19$ & $2.32 \pm 0.08$ & $3.06^{c} \pm 0.03$ & $2.59 \pm 0.05$ \\
\hline Fiber & $14.24 \pm 0.07$ & $8.12 \pm 0.30$ & $16.31 \pm 0.58$ & $11.11 \pm 0.22$ & $17.89 \pm 0.99$ & $13.49 \pm 0.44$ & $22.00 \pm 0.13$ & $14.30 \pm 0.72$ \\
\hline \multicolumn{9}{|c|}{ Mineral Composition of Buckwheat (mg/100 gm, as is basis) } \\
\hline Iron & $5.50 \pm 0.02$ & $5.30 \pm 0.25$ & $5.50 \pm 0.10$ & $4.20 \pm 0.20$ & $6.40 \pm 0.25$ & $3.10 \pm 0.20$ & $7.30 \pm 0.20$ & $2.70 \pm 0.10$ \\
\hline Potassium & $230.0 \pm 5.0$ & $149.01 \pm 3.60$ & $208.33 \pm 7.63$ & $188.01 \pm 1.73$ & $234.33 \pm 3.51$ & $220.02 \pm 4.0$ & $242.00 \pm 4.35$ & $258.01 \pm 6.02$ \\
\hline Zinc & $9.66 \pm 0.15$ & $8.73 \pm 0.20$ & $11.07 \pm 0.17$ & $10.83 \pm 0.06$ & $12.18 \pm 0.15$ & $13.82 \pm 0.06$ & $13.05 \pm 0.14$ & $13.98 \pm 0.11$ \\
\hline Calcium & $55.08 \pm 1.01$ & $38.01 \pm 0.11$ & $42.01 \pm 0.80$ & $29.00 \pm 0.52$ & $58.02 \pm 0.45$ & $35.01 \pm 0.09$ & $67.09 \pm 0.47$ & $47.02 \pm 0.50$ \\
\hline Magnesium & $229.00 \pm 3.60$ & $121.01 \pm 3.21$ & $106.00 \pm 3.60$ & $144.06 \pm 4.50$ & $141.07 \pm 3.21$ & $161.02 \pm 3.60$ & $194.04 \pm 4.04$ & $161.01 \pm 3.60$ \\
\hline $\begin{array}{c}\text { Total Amylose } \\
(\%)\end{array}$ & $20.84 \pm 0.26$ & $\begin{array}{l}23.86 \\
\pm 0.88\end{array}$ & $\begin{array}{l}19.52 \\
\pm 0.53\end{array}$ & $\begin{array}{l}23.47 \\
\pm 0.49\end{array}$ & $\begin{array}{l}18.75 \\
\pm 0.67\end{array}$ & $\begin{array}{l}22.48 \\
\pm 0.48\end{array}$ & $\begin{array}{l}17.71 \\
\pm 0.63\end{array}$ & $21.60 \pm 0.60$ \\
\hline
\end{tabular}

HC -Husked Control buckwheat flour; HTA-Husked 5 min parboiled flour(Treatment A); HTB - Husked 10 min parboiled flour (Treatment B); HTC- Husked 15 min parboiled flour(Treatment C); DHC -Dehusked Control buckwheat flour; DHTA- Dehusked 5 min parboiled flour(Treatment A); DHTB- Dehusked 10 min parboiled flour (Treatment B); DHTC- Dehusked 15 min parboiled flour (Treatment C).

Means and Standard deviation of triplicate values are given. Values within the rows with same super script are not significantly different $(\mathrm{P} \leq 0.05)$

Table 2: Proximate and mineral composition of Husked and Dehusked buckwheat flour( $\mathrm{g}$ per $100 \mathrm{~g}$ as is basis). 
humans, iron is an essential component of hundreds of proteins and enzymes [23]. The iron content increased (32\%) as the duration of parboiling increased, in the husked, whereas in the dehusked a decrease (49\%) was observed. No significant difference was found between potassium content in HC, HTB, HTC and DHTB. The potassium content increased as the duration of parboiling increased in husked as well as dehusked. As evident from Table 4, there was no significant difference between HC and DHTA. Significant difference was also not observed between treatment DHTB and DHTC. An increase in zinc content was observed for the husked and dehusked as the duration of parboiling increased. In case of calcium, as evident from the Table 2 , significant difference was observed for the husked and dehusked flours, in all the treatments. In the case of Magnesium, there was no significant difference between HTB and DHTA. In a study conducted by Amarowicz et al.[22], it was observed that, compared to cereal grain, buckwheat seed coat is rich in iron and manganese, and when compared to whole buckwheat grain it contains less zinc, copper and potassium and manganese. Hence it can be assumed that buckwheat endosperm is very rich in mineral salts and removing seed coat does not affect qualitative-quantitative composition of flours mineral salts. Compared to flour, buckwheat groats were found to contain less zinc, manganese and iron, and more potassium and magnesium. These points to the possibility of migrating of these elements from seed coat to the endosperm during hydrothermic treatment. Compared to flour buckwheat groats were found to contain less zinc, manganese and iron, and more potassium and magnesium. The amylose content (Table 2) is one of the most important determinants of quality of grains. The amylose content was higher in dehusked flour samples as compared to husked. However a gradual decline in amylase (Table 2) was observed as the duration of parboiling increased, both for the husked (15\%) as well as the dehusked flours (9.47\%).

\section{Polyphenols}

Buckwheat seeds and plant tissues are good sources of many phenolic compounds, particularly phenolic acids and flavonoids [24,25]. These compounds are present in both free and bound forms and their levels are influenced by environmental factors and cultivar [26,27]. The yield of extraction of phenolic compounds depends on factors such as the chemical nature of the compounds, the type of solvent, as well as the time and temperature of extraction [28]. The highest antioxidant activity in buckwheat grains was recorded in methanol extracts. As evident from supplementary Table 2, polyphenols were higher for the husked flour in both the free and bound form (183.96) as compared to dehusked, free (64.94) and bound (59.24).

\section{Functional properties of the flour}

The functional properties, viz swelling power and solubility are presented in Table 3. The swelling power of starch has been reported to depend on water holding capacity of starch molecules by hydrogen bonding [29] and depends on the amylose content. When starch is heated in excess water, their crystalline structure is disrupted. The water molecules get linked, by hydrogen bonding, to the exposed hydroxyl group of amylose and amylopectin, which causes an increase in granule swelling and solubility [30]. The granules become increasingly susceptible to shear disintegration as they swell, and they release soluble material as they disintegrate. Solubility is the leaching out of linear molecules of amylose or linear portions of long branched chains of amylopectin at or above gelatinization temperature. In the present investigation, results revealed the $\%$ solubility and swelling power increased as the temperature increased, both for husked as well as dehusked flours. The swelling power was higher in the parboiled flours as compared to the control flour samples. Unnikrishnan and Bhattacharya [12] reported that the parboiled rice flour swelled and dissolved more than raw rice flour in water at temperature below $70^{\circ} \mathrm{C}$, but less than raw rice at higher temperature. The high swelling power and solubility observed in the parboiled buckwheat flour samples indicate the higher susceptibility of its starch granules to disintegration than that the control flour sample, leading to leaching of linear molecules. Excessive leaching of starch molecules can also be attributed to shorter average amylopectin chain lengths [31]. The low swelling power and solubility of control buckwheat flour samples (Table 3 ) suggest the presence of stronger bonding forces within the interiors of the starch granules and more amylose lipid complex [32]. Ong et al. [33] inferred that long chains of amylopectin interact with amylose to form double helix structures that lower the swelling and leaching of materials on cooking. This may also be responsible for low solubility and swelling power of parboiled rice flours as compared to control. Study conducted by Soren et al. $[16,17]$, revealed that, buckwheat starch differed from cereal starches and that steam hydrothermal processing resulted in considerable changes in chemical composition, properties and structure of the starch. Study conducted by Hang et al. revealed, that structure and physico chemical properties of Tartary Buckwheat Starch can be modified by heat moisture treatment, to improve its thermal stability and extend its application range. Min et al. [34], studied the functional characterization of steam jet cooked buckwheat flour as a fat replacer in cake baking. Steam jet-cooking caused structural breakdown and starch gelatinization of

\begin{tabular}{|c|c|c|c|c|c|c|c|c|}
\hline $\begin{array}{c}\text { Temperature } \\
\left({ }^{\circ} \mathrm{C}\right)\end{array}$ & $\begin{array}{c}\text { Control } \\
\text { Husked } \\
\text { (HC) }\end{array}$ & $\begin{array}{l}\text { Control } \\
\text { Dehusked } \\
\text { (DHC) }\end{array}$ & $\begin{array}{c}\text { Treatment A } \\
\text { Husked } \\
\text { (HTA) }\end{array}$ & $\begin{array}{c}\text { Treatment A } \\
\text { Dehusked } \\
\text { (DHTA) }\end{array}$ & $\begin{array}{c}\text { Treatment B } \\
\text { Husked } \\
\text { (HTB) }\end{array}$ & $\begin{array}{c}\text { Treatment B } \\
\text { Dehusked } \\
\text { (DHTB) }\end{array}$ & $\begin{array}{c}\text { Treatment C } \\
\text { Husked } \\
\text { (HTC) }\end{array}$ & $\begin{array}{c}\text { Treatment C } \\
\text { Dehusked } \\
\text { (DHTC) }\end{array}$ \\
\hline $30^{\circ} \mathrm{C}$ & $9.62 \pm 0.39$ & $8.53 \pm 0.48$ & $11.24 \pm 0.08$ & $10.64 \pm 0.53$ & $10.80 \pm 0.16$ & $10.66 \pm 0.22$ & $9.84 \pm 0.15$ & $12.45 \pm 0.29$ \\
\hline $45^{\circ} \mathrm{C}$ & $10.27 \pm 0.33$ & $9.13 \pm 0.40$ & $11.69 \pm 0.71$ & $10.15 \pm 0.67$ & $12.30 \pm 0.76$ & $11.10 \pm 0.27$ & $10.11 \pm 0.61$ & $12.80 \pm 0.83$ \\
\hline $60^{\circ} \mathrm{C}$ & $11.81 \pm 1.03$ & $9.19 \pm 0.42$ & $11.87 \pm 0.88$ & $11.31 \pm 0.67$ & $11.22 \pm 0.88$ & $11.31 \pm 0.49$ & $9.18 \pm 0.43$ & $11.95 \pm 0.89$ \\
\hline $75^{\circ} \mathrm{C}$ & $11.85 \pm 1.00$ & $10.27 \pm 0.53$ & $12.22 \pm 0.61$ & $11.37 \pm 0.56$ & $11.68 \pm 0.66$ & $12.15 \pm 0.56$ & $10.19 \pm 0.35$ & $12.89 \pm 0.58$ \\
\hline $90^{\circ} \mathrm{C}$ & $12.76 \pm 0.58$ & $13.04 \pm 0.09$ & $16.10 \pm 0.60$ & $14.23 \pm 0.67$ & $14.07 \pm 0.74$ & $14.92 \pm 0.21$ & $13.27 \pm 0.48$ & $16.26 \pm 0.63$ \\
\hline \multicolumn{9}{|c|}{ Swelling Power of Husked and Dehusked buckwheat flour } \\
\hline $30^{\circ} \mathrm{C}$ & $3.35 \pm 0.54$ & $2.47 \pm 0.42$ & $3.85 \pm 0.95$ & $3.82 \pm 0.55$ & $4.45 \pm 0.57$ & $4.63 \pm 0.32$ & $4.80 \pm 0.26$ & $4.81 \pm 0.25$ \\
\hline $45^{\circ} \mathrm{C}$ & $3.08 \pm 0.16$ & $2.58 \pm 0.33$ & $3.68 \pm 0.27$ & $4.04 \pm 0.09$ & $4.52 \pm 0.50$ & $4.44 \pm 0.19$ & $4.88 \pm 0.54$ & $4.79 \pm 0.24$ \\
\hline $60^{\circ} \mathrm{C}$ & $3.85 \pm 0.37$ & $3.68 \pm 0.68$ & $4.40 \pm 0.51$ & $4.84 \pm 0.25$ & $5.27 \pm 0.62$ & $5.54 \pm 0.30$ & $5.58 \pm 0.42$ & $6.67 \pm 0.36$ \\
\hline $75^{\circ} \mathrm{C}$ & $7.62 \pm 0.44$ & $6.98 \pm 0.13$ & $6.80 \pm 0.73$ & $6.36 \pm 0.25$ & $5.51 \pm 0.44$ & $6.62 \pm 0.90$ & $5.59 \pm 0.50$ & $5.66 \pm 0.28$ \\
\hline $90^{\circ} \mathrm{C}$ & $8.38 \pm 0.45$ & $9.08 \pm 0.23$ & $7.20 \pm 0.26$ & $7.72 \pm 0.56$ & $6.71 \pm 0.62$ & $7.09 \pm 0.23$ & $6.70 \pm 0.44$ & $6.55 \pm 0.44$ \\
\hline
\end{tabular}

Means and Standard deviation of triplicate values are given. Values within the rows with same super script are significantly different $(\mathrm{P} \leq 0.05)$.

Table 3: Percent Solubility and Swelling power of Husked and Dehusked buckwheat flour 


\begin{tabular}{|c|c|c|c|c|c|c|c|c|}
\hline Colour & $\begin{array}{c}\text { Control } \\
\text { Husked (HC) }\end{array}$ & $\begin{array}{c}\text { Control } \\
\text { Dehusked (DHC) }\end{array}$ & $\begin{array}{c}\text { Treatment A } \\
\text { Husked (HTA) }\end{array}$ & $\begin{array}{c}\text { Treatment A } \\
\text { Dehusked (DHTA) }\end{array}$ & $\begin{array}{c}\text { Treatment B } \\
\text { Husked (HTB) }\end{array}$ & $\begin{array}{c}\text { Treatment B } \\
\text { Dehusked (DHTB) }\end{array}$ & $\begin{array}{c}\text { Treatment C } \\
\text { Husked (HTC) }\end{array}$ & $\begin{array}{c}\text { Treatment C } \\
\text { Dehusked (DHTC) }\end{array}$ \\
\hline L $^{*}$ & $70.50 \pm 0.10$ & $82.22 \pm 0.01$ & $66.29 \pm 0.24$ & $78.21 \pm 0.22$ & $64.43 \pm 0.36$ & $77.64 \pm 0.47$ & $63.67 \pm 0.48$ & $76.42 \pm 0.39$ \\
\hline $\mathbf{a}^{*}$ & $2.74 \pm 0.02$ & $1.51 \pm 0.00$ & $3.15 \pm 0.01$ & $2.22 \pm 0.01$ & $3.42 \pm 0.01$ & $2.34 \pm 0.01$ & $3.31 \pm 0.01$ \\
\hline $\mathbf{b}^{*}$ & $10.66 \pm 0.02$ & $9.81 \pm 0.02$ & $11.44 \pm 0.01$ & $12.07 \pm 0.02$ & $12.14 \pm 0.00$ & $12.20 \pm 0.00$ & $11.43 \pm 0.02$ & $12.45 \pm 0.01$ \\
\hline DE & $29.41 \pm 0.01$ & $18.61 \pm 0.01$ & $33.70 \pm 0.00$ & $23.27 \pm 0.01$ & $36.11 \pm 0.00$ & $24.26 \pm 0.00$ & $35.96 \pm 0.00$ & $24.59 \pm 0.01$ \\
\hline Particle & 344.87 & 341.13 & 345.87 & 378.84 & 334.87 & 352.84 \\
size & \pm 1.15 & \pm 0.96 & \pm 0.57 & \pm 0.62 & \pm 1.07 & 331.71 \\
\hline
\end{tabular}

Means and Standard deviation of triplicate values are given. Values within the rows with same super script are not significantly different (P $\geq 0.05)$

Table 4: Color and particle size measurement of Buckwheat flour

\begin{tabular}{|c|c|c|}
\hline Colour of Biscuits & Husked & Dehusked \\
\hline $\mathbf{L}^{*}$ & $35.94 \pm 0.07$ & $59.44 \pm 0.47$ \\
\hline $\mathbf{a}^{*}$ & $8.15 \pm 0.05$ & $7.34 \pm 0.07$ \\
\hline $\mathbf{b}^{*}$ & $16.07 \pm 0.14$ & $26.40 \pm 0.39$ \\
\hline DE & $63.33 \pm 0.45$ & $46.30 \pm 0.57$ \\
\hline Textural profile of biscuits Force( KiloNewton) & $35.54 \pm 0.03$ & $22.00 \pm 0.30 \pm 0.02$ \\
\hline
\end{tabular}

Means and Standard deviation of triplicate values are given. All the values were found to be significantly different $(P \leq 0.05)$

Table 5: Color and Textural measurement of Biscuits

buckwheat flour, thus increasing its water hydration properties. When shortening in cakes was replaced with steam jet-cooked buckwheat gels, the specific gravity of cake batters significantly increased, consequently affecting cake volume after baking. Skrabanja et al. [35] reported that buckwheat groats prepared by using the traditional procedure of cooking before dehusking followed by warm-air drying, have less than $48 \%$ (dmb) of rapidly available starch, in comparison to white wheat bread, where the corresponding value is almost $59 \%$. Buckwheat groats starch with a reduced rate of digestion could be a possible complement to or a substitute for common carbohydrate sources.

\section{Scanning electron microscopy}

Morphological characteristics like shape, size and distribution of starch granules are attributed to the biological origin of the grain [36]. Earlier studies by Pomeranz and Sachs [37] confirmed that the composition and gross structure of dehulled buckwheat resembles that of the naked cereal grain. SEM images of Dehusked and Husked are presented in Figure 1. The individual granules were irregular (dehuskedA, B, C and D); with noticeable flat areas due to compact packing in the grain endosperm. Some spherical starch granules were also present. As regards to the size, most frequent were granules with diameter 3-7 $\mu \mathrm{m}$. In the case of parboiled flours B, C and D, few agglomerated structures were observed. Few sporadic breakings were observed in these images which might be due to starch swelling due to hydrothermal treatment. The same changes were observed for the husked flours, in which the control sample (E) was intact, whereas the other parboiled samples (F, $\mathrm{G}$ and $\mathrm{H}$ ) were agglomerated and breakings were observed. As regards to the size, most frequent were granules with diameter 5-9 $\mu \mathrm{m}$. Under the effect of water and high temperature, starch granules underwent gelatinization. From the images, the various phases of gelatinization were visible, as the duration of parboiling increased.

\section{Flour characteristics}

Colour: The colour of the product was measured in accordance with CIE L', a*, b*colour space system (Lab Scan XE Hunter Lab instruments, Virginia, USA) based on the tristimulus value. Here $\mathrm{L}^{*}$, $\mathrm{a}^{*}, \mathrm{~b}^{*}$, and DE indicates lightness, redness, yellowness and darkness respectively. The Control sample of buckwheat was brighter in husked as well as dehusked as compared to the parboiled samples but redness and yellowness was less as compared to the parboiled samples (Table 4). However no significant difference was observed in brightness between
DHTA and DHTB and between HTB and HTC. As the duration of parboiling increased the brightness decreased and darkness increased for the husked and the dehusked flours. Dehusked samples were brighter as compared to husked buckwheat flour samples.

Particle size of the samples: Particle size of the husked sample was higher than dehusked and germinated flour samples (Table 4). Germinated sample had minimum particle size. Particle size of the samples shows a gradual decrease as the duration of parboiling increased. No significant difference between HC and HTA and between DHC and DHTC. Thus it can be concluded, that parboiling decreased the particle size of the sample.

\section{Sensory analysis, colour and texture of biscuits}

Quantitative Descriptive Analysis (QDA) method was employed for profiling the samples. Results of sensory analysis (Supplementary Figures 1 and 2) indicated that there was a significant difference in color between the biscuit samples. Sample A was light brown in color (5.5) while B and C were darker in color (8.6 and 10.6 respectively). Texture, in terms of hardness, fracturability, crispness and crumbliness showed some variation in sample B and C. Sample C was comparatively hard in texture followed by B. It was also observed that all the samples had perceptible baked cereal aroma note. However sample A, had good baked cereal aroma, vanilla and sweetness compared to sample B and $\mathrm{C}$ which are the desirable qualities for biscuits. Based on desirable quality attributes such as color, crispness and less of hardness, sample A was rated high for overall quality (9.2) which was significantly higher than that of sample B and C. Biscuits prepared from dehusked flour sample were brightest in color, as compared to germinated and husked flour (Table 5). Redness was less in all the samples as compared to yellowness. The force required, was maximum for breaking the biscuits prepared from husked flour, followed by germinated flour biscuit, and minimum for biscuits from dehusked flour sample (Table 5). Thus biscuits from dehusked samples had soft texture as compared to husked and germinated flour biscuit.

\section{Conclusion}

From the present investigation, it can be concluded that, hydrothermal treatment had a beneficial effect on the nutrient composition and functional properties of buckwheat flour. The dehusked flour was nutritionally rich as compared to husked flour. The 
Citation: Pandey S, Senthil A, Fatema K (2015) Effect of Hydrothermal Treatment on the Nutritional and Functional Properties of Husked and Dehusked Buckwheat. J Food Process Technol 6: 461. doi:10.4172/2157-7110.1000461

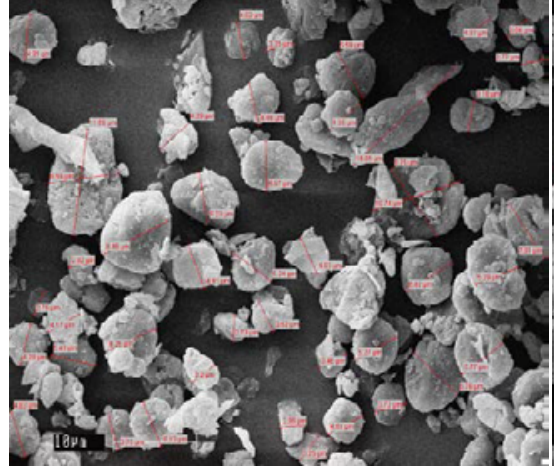

A $(\times 5000$ scale bar $=10 \mu \mathrm{m})$

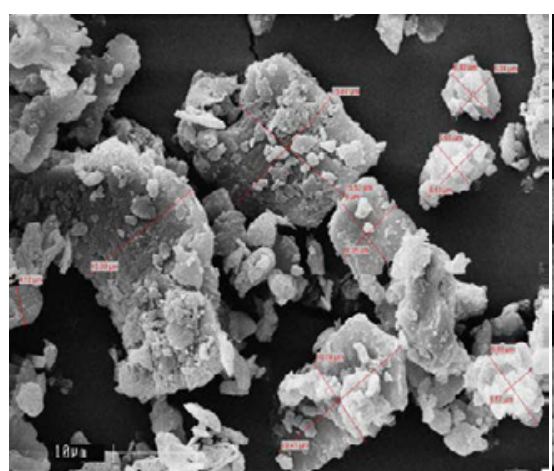

$\mathrm{C}(\times \mathbf{5 0 0 0}$ scale bar $=10 \mu \mathrm{m})$

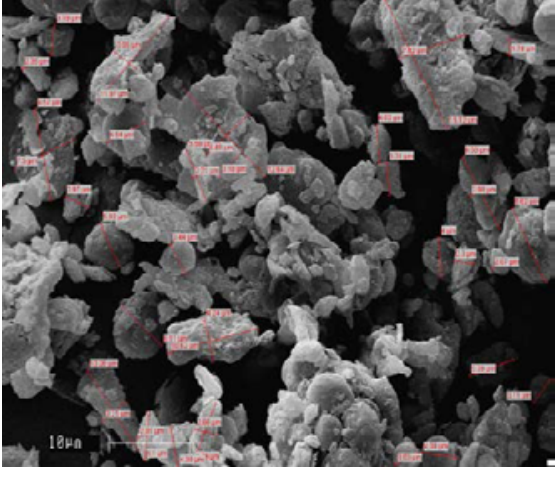

B $(\times 5000$ scale bar $=10 \mu \mathrm{m})$

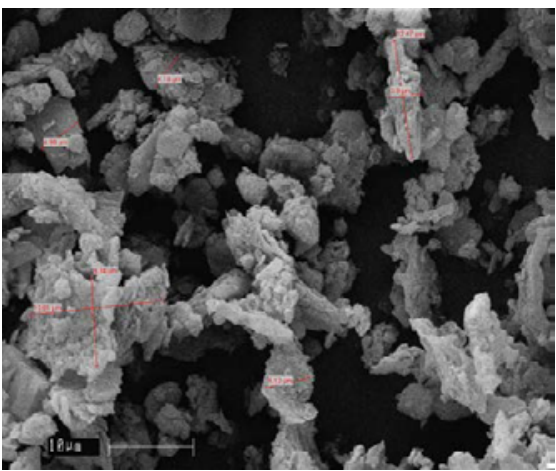

D $(\times 5000$ scale bar $=10 \mu \mathrm{m})$

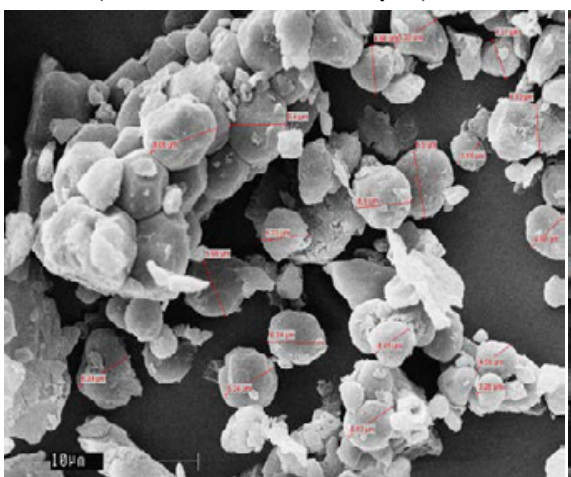

E $(\times 5000$ scale bar $=10 \mu \mathrm{m})$

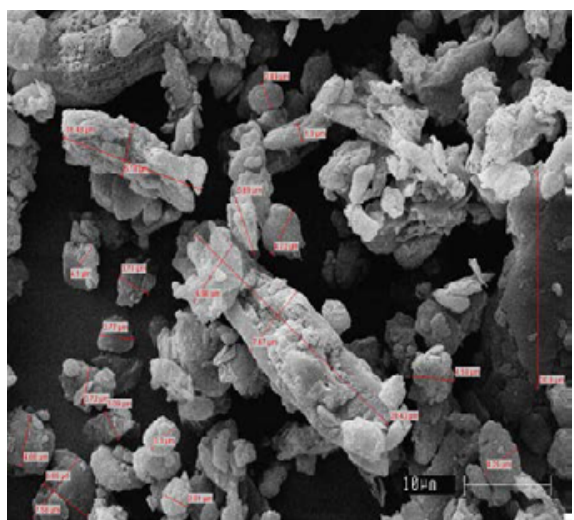

G $(\times 5000$ scale bar $=10 \mu \mathrm{m})$

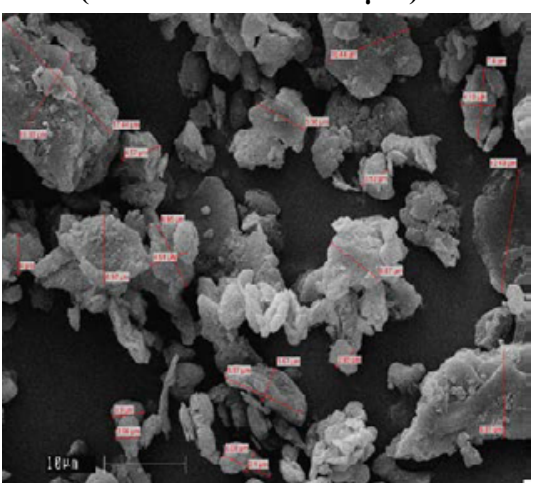

F $(\times 5000$ scale bar $=10 \mu \mathrm{m})$

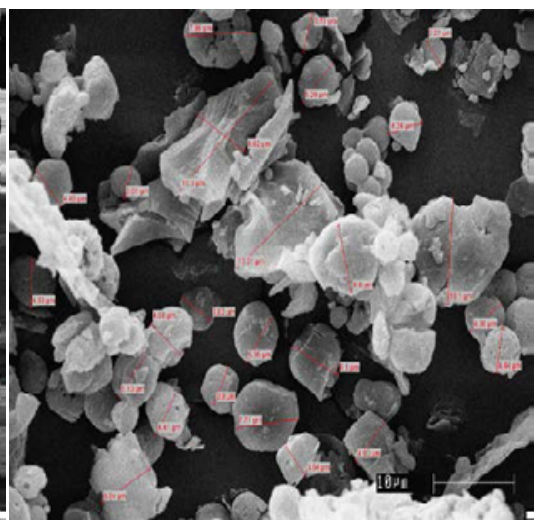

H $(\times 5000$ scale bar $=10 \mu \mathrm{m})$

Figure 1: SEM images of Husked and Dehusked buckwheat flours; (A) Husked Control buckwheat flour (HC); (B) Treatment A (HTA); (C) Treatment B (HTB); (D) Treatment C (HTC); (E) Dehusked Control buckwheat flour (DHC); (F) Treatment A (DHTA); (G) Treatment B (DHTB); (H) Treatment C (DHTC). 
Citation: Pandey S, Senthil A, Fatema K (2015) Effect of Hydrothermal Treatment on the Nutritional and Functional Properties of Husked and Dehusked Buckwheat. J Food Process Technol 6: 461. doi:10.4172/2157-7110.1000461

flour had a fine particle size and pleasant colour. The product developed from the husked control flour was found to be acceptable by the judges.

\section{Acknowledgement}

The authors acknowledge with thanks the financial support and co-operation received from Director, CSIR-Central Food Technological Research Institute, Mysore, Karnataka, India.

\section{References}

1. Li SQ, Zhang QH (2001) Advances in the development of functional foods from buckwheat. Critical Reviews in Food Science and Nutrition 41: 451-464.

2. Khan F, Zeb A, Arif M, Ullah J, Wahab S (2012) Preparation and evaluation of gluten free ready to serve buckwheat product. Journal of Agricultural and Biological Science 7: 633-637.

3. Tahir I, Farooq S (1988) Review article on buckwheat. Fagopyrum 8: 33-53.

4. Krkoskova B, Mrazova Z (2005) Prophylactic components of buckwheat. Food Research International 38: 561-568.

5. Oomah BD, Mazza G (1996) Flavonoids and antioxidative activities in buckwheat. Journal of Agricultural and Food Chemistry 44: 1746-1750.

6. Wijngaard HH, Arendt EK (2006) Buckwheat. Cereal Chemistry 83: 391-401.

7. Henry CJK, Massey D (2001) Micronutrient changes during processing and storage. Crop post harvest programme.

8. Bhattacharya KR, Sowbhagya CM, Indudhara Swamy YM (1972) Some physical properties of paddy and rice and their interrelations. Journal of Science Food and Agriculture 23: 171-186.

9. AOAC (2000) Official Methods of Analysis of AOAC International (17th Ed.) Gaitherburg, USA.

10. Englyst HN, Hudson GJ (1996) The classification and measurement of dietary carbohydrates. Food Chemistry 57: 15-21.

11. Singleton VL, Orthofer R, Lamuela-Raventos RM (1999) Analysis of tota phenols and other oxidation substrates and antioxidants by means of FolinCiocalteu reagent. Methods Enzymol 299: 152-178.

12. Unnikrishnan KR, Bhattacharya KR (1981) Swelling and solubility behavior of parboiled rice flour. International Journal of Food Science and Technology 16 403-408.

13. Sowbhagya CM, Bhattacharya KR (1979) A simplified colorimetric method for determination of amylose content in rice. Starch 23: 53-56.

14. De-Francisco A, Kreft, I (1989) Morphological studies on the location and size of the buckwheat embryo. Fagopyrum 9: 47-48.

15. Steadman KJ, Burgoon MS, Lewis BA, Edwardson SE, Obendorf RL (2001) Buckwheat seed milling fractions: Description, macronutrient composition and dietary fibre. Journal of Cereal Science 33: 271-278.

16. Soral-Smietana M, Fornal N, Fornal J (1984) Characteristics of buckwheat grain starch and effect of hydrothermal processing on its chemical composition, properties and structure. Starch 36: 153-158

17. Soral-Smietana M, Fornal N, Fornal J (1984) Characteristics of lipids in Buckwheat grain and isolated starch and their changes after hydrothermal processing. Food/ Nahrung 28: 483-492.

18. Bonafaccia G, Marocchini M, Kreft I (2003) Composition and technologica properties of the,flour and bran from common and tartary buckwheat. Food Chemistry 80: 9-15.

19. Eggum BO, Kreft I, Javornik B (1981) Chemical composition and protein quality of buckwheat (Fagopyrum esculentum Moench). Plant Foods Hum. Nutrition 30: $175-179$

20. Alvarez-Jubete L, Arendt EK, Gallagher E (2009) Nutritive value and chemical composition of pseudocereals as gluten-free ingredients. International Journal of Food Sciences and Nutrition 60: 240-257.

21. Ikeda S, Yamashita Y (1994) Buckwheat as a dietary source of zinc, copper and manganese. Fagopyrum 14: 29-34.

22. Amarowicz R, Fornal L (1987) Characteristics of buckwheat grain minera components and dietary fiber. Fagopyrum 7: 3-6.
23. Fairbanks F (1999) Iron in Medicine and Nutrition, Williams and Wilkins publishing company, Baltimore, USA

24. Holasova M, Fiedlerova V, Smrcinova H, Orsak M, Lachman J, et al. (2002) Buckwheat-the source of antioxidant activity in functional foods. Food Research International 35: 207-211.

25. Przybylski R, Lee YC, Eskin NAM (1998) Antioxidant and radical-scavenging activities of buckwheat seed components. Journal of the American Oil Chemists Society 75: 1595-1601.

26. Kitabayashi H, Ujihara A, HiroseT, Minami M (1995) Varietal differences and heritability for rutin content in common buckwheat, Fagopyrum esculentum Moench. Jpn J Breed 45: 75-79.

27. Ohsawa R, Tsutsumi T (1995) Inter-varietal variations of rutin content in common buckwheat flour (Fagopyrum esculentumMoench). Euphytica 86: 183-189.

28. Sun T, Ho CT (2005) Antioxidant activities of buckwheat extracts. Food Chemistry 90: 743-749.

29. Lee YE, Osman EM (2003) Pasting and crystalline property differences of commercial and isolated rice starch with added amino acids. Journal of Food Science 68: 832-838.

30. Singh N, Singh J, Kaur L, Sodhi NS, Gill BS (2003) Morphological, thermal and rheological properties of starches from different botanical sources. Food Chemistry 81: 219-231.

31. Mizukami H, Takeda $\mathrm{Y}$, Hizukari S (1999) The structure of the hot wate soluble components in the starch granules of new Japanese rice cultivars. Carbohydrate Polymers 38: 329-335.

32. Tester RF, Morrison WR (1990) Swelling and gelatinization of cereal starches Cereal Chemistry 67: 551-558.

33. Ong MH, Blanshard JMV (1995) Texture determinants of cooked, parboiled rice II. Physicochemical properties and leaching behavior of rice. Journal of Cereal Science 21: 261-269.

34. Min B, Lee SM, Yoo SH, Inglett GE, Lee S (2010) Functional characteristics of steam jet cooked buckwheat flour as a fat replacer in cake baking. J Sci Food Agric 90: 2208-2213

35. Skrabanja V, Laerke HN, Kreft I (1998) Effects of Hydrothermal Processing of Buckwheat (Fagopyrum esculentum Moench) Groats on Starch Enzymatic Availability In Vitro and In Vivo in Rats. Journal of Cereal Science 28: 209-214.

36. Vandeputte GE, Delcour JA (2004) From sucrose to starch granule to starch physical behaviour: A focus on rice starch. Carbohydrate Polymers 58: 245266.

37. Pomeranz Y, Sachs JB (1972) Scanning electron microscopy of the buckwheat Cereal Chem 49: 23-25. 